\title{
Influence of gonadal hormones on odours emitted by male meadow voles (Microtus pennsylvanicus)
}

\author{
M. H. Ferkin*, M. R. Gorman and I. Zucker \\ Department of Psychology, University of California, Berkeley, CA 94720, USA
}

\begin{abstract}
Summary. Free-living male meadow voles (Microtus pennsylvanicus) emit odours that are attractive to females at the beginning, but not at the end, of the breeding season. The effect of gonadal hormones on female-attractant cues was examined in males born and reared in long $\left(14 \mathrm{~h}\right.$ light $\left.\mathrm{day}^{-1}\right)$ and short $\left(10 \mathrm{~h} \mathrm{light} \mathrm{day}^{-1}\right)$ photoperiods that simulate daylengths in the breeding and nonbreeding seasons, respectively. Gonadectomy affected the attractant properties of odours emitted by long photoperiod, but not short photoperiod, males. Long photoperiod females preferred odours of intact rather than those of gonadectomized long photoperiod males, and odours of gonadectomized long photoperiod males rather than those of intact short photoperiod males. Females did not show a preference between the odours of intact and castrated short photoperiod males. Gonadal hormone replacement in males affected female responses to the odours emitted by long photoperiod, but not short photoperiod, gonadectomized males. Long photoperiod females did not display a preference between odours of intact long photoperiod males and gonadectomized long photoperiod males treated with testosterone or oestradiol. We conclude that in spring and summer gonadal hormones increase attractiveness of male odours; this effect may require aromatization of testosterone to oestradiol. Substrates that control attractiveness of odour cues in male voles appear to be unresponsive to androgens during the nonbreeding season.
\end{abstract}

Kelwords: odour preferences: photoperiod; seasonality; vole; steroids

\section{Introduction}

Meadow voles (Microtus pennsylvanicus) undergo seasonal changes in social organization, social tolerance and spacing behaviour (Madison \& McShea, 1987). Odour cues emitted by individuals and their preferences for certain conspecific odours (odour preferences; Ferkin \& Seamon, 1987) both vary seasonally. Adult meadow voles emit odours attractive to the opposite sex during the breeding season, but not during the season of reproductive quiescence (Ferkin \& Seamon, 1987). During the late autumn and winter most breeding ceases (Christian, 1980) and female meadow voles prefer odours of females rather than those of males and transmit odours attractive to other females; males do not display a preference between male and female odours during this time (Ferkin \& Seamon, 1987; Ferkin, 1988). Generally, odour preferences and cues are complementary: voles emit odours that are attractive to conspecifics to whom they in turn are attracted (Ferkin \& Zucker, 1991; Ferkin et al., 1991). This relationship may be important in regulating breeding and coordinating social organization (Ferkin \& Seamon, 1987).

In female meadow voles, changes in ovarian hormone concentrations induced by photoperiod mediate seasonal shifts in odour preferences and odour cue emissions. Briefly, ovariectomy abolishes the preference for male odours in long-photoperiod females. The preference for male

*Present address: Psychology Department, Cornell University, Ithaca, NY 14853, USA. 
odours is restored in long-day females, but is not induced in short-day females treated with oestradiol (Ferkin \& Zucker, 1991). Ovariectomy also negates the male-attractant property of long photoperiod female odours. Oestradiol treatment renders odours emitted by both long- and shortday ovariectomized females attractive to males and in this respect females in short daylengths are not refractory to the effects of oestrogen (Ferkin et al., 1991).

Hormones influence odour-producing tissues and glands in male rodents (Strauss \& Ebling, 1970; Ebling, 1972; Brown, 1985a, b). Odour-producing glands increase in size and secretory activity at puberty and during the breeding season when androgen concentrations are high (Quay, 1968; Christiansen et al., 1978; Jannett, 1978; Adams et al., 1980). Castration results in a decrease in the development and reduced secretory activity by specialized glands and tissues in the integument; these changes are reversed by androgen replacement (Jannett, 1978; Powers et al., 1985; Rowsemitt et al., 1988; Johnston, 1990; Miernicki et al., 1990). Pituitary hormones may also affect odour production (Thody \& Shuster, 1975; Keverne, 1981), independently of or synergistically with androgens (Ebling et al., 1975; Thody et al., 1976).

Hormonal control of odour production and emission in male meadow voles has not been established. In a previous study, long photoperiod females preferred the odours emitted by long photoperiod males to those of short photoperiod males (Ferkin \& Zucker, 1991). Long and short photoperiods used in that study simulated daylengths prevalent in the breeding and nonbreeding season, respectively. Variations in photoperiod corresponding to seasonal variations in daylength suggest the latter may be sufficient to effect changes in the attractiveness of male cues, and this may be mediated by seasonal fluctuations in gonadal hormone secretion. Males born in spring and early summer grow rapidly, reach puberty, and mate within 2 months of birth, whereas those born in the autumn grow more slowly, do not reach puberty until 6-8 months of age, and first mate in the following spring (Christian, 1980). Androgen concentrations in voles are significantly higher in the breeding than in the nonbreeding season (Adams et al., 1980; Rowsemitt \& Berger, 1983). Male odours are sufficient to induce behavioural oestrus and facilitate breeding in female voles (Clulow \& Mallory, 1970; Carter et al., 1987).

Among meadow voles, odour cues and odour preferences may facilitate reproduction, territoriality during the breeding season, and communal nesting and reproductive quiescence during the nonbreeding season. In this study, we compared female-attractant cues in the odours transmitted by males maintained in daylengths that simulate those of the breeding and nonbreeding season, respectively, and investigated whether changes in steroid hormone concentrations effected by gonadectomy influence the attractiveness of male odours to female meadow voles.

\section{Materials and Methods}

\section{Animals}

Adult ( $70-120$ day old) male and female meadow voles born and maintained in long photoperiods were paired and placed in rooms that provided either 14 (long photoperiod) or 10 (short photoperiod) h light day ${ }^{-1}$, respectively (lights on at 07.00 and $09.00 \mathrm{~h}$, respectively). The subsequent litters remained in their respective natal photoperiods, were weaned at 18 days of age, housed with littermates until 35 days of age, and singly thereafter in opaque plastic cages $\left(13 \times 16 \times 31 \mathrm{~cm}^{3}\right)$. Wood shavings, cotton nesting material, food (Purina mouse chow no. 5015, Ralston Purina $\mathrm{Co}$., St Louis, MO) and water were provided ad libitum and room temperature was maintained at $22 \pm 2{ }^{\circ} \mathrm{C}$. Cages were cleaned twice a week and the cotton nesting material replaced once a week.

\section{Surgical procedure}

Males, approximately 70 days of age, were anaesthetized with a ketamine 'cocktail' (2.5 mg ketamine hydrochloride in $0.12 \mathrm{ml}, 0.3 \mathrm{mg}$ xylazine in $0.12 \mathrm{ml}$, and $0.33 \mathrm{mg}$ acetylpromazine in $0.12 \mathrm{ml}$ ); $0.04 \mathrm{ml}$ of cocktail was injected i.p. per $10 \mathrm{~g}$ of body weight. Testes were removed via a midline incision; the blood vessels to the testes were ligated with sterile sutures, the testes excised and the abdominal wall and skin closed separately with sterile sutures 
and treated with $0 \cdot 2 \%$ nitrofurazone (Furacin). Postoperative discomfort was alleviated by administration of codeine-acetaminophen solution in the drinking water on days $1-4$ after surgery.

\section{Hormone replacement}

Capsules were made from Silastic tubing (Dow Corning, Midland, MI; o.d. 0.077 in, i.d. 0.058 in), cut into $20 \mathrm{~mm}$ lengths, and filled with crystalline testosterone (Sigma Chemical Co., St Louis, MO). The ends of the capsules were plugged with $5 \mathrm{~mm}$ dowels and sealed with silicon rubber cement, leaving $10 \mathrm{~mm}$ lengths of testosterone-filled tubing. Oestradiol (Sigma Chemical Co.) capsules were prepared in a similar way but were $15 \mathrm{~mm}$ and contained $5 \mathrm{~mm}$ lengths of hormone-filled tubing. Blank capsules were similar to the testosterone capsules but were left empty. Blank, testosterone-filled and oestradiol-filled capsules were incubated separately in saline for $24 \mathrm{~h}$ before insertion into the voles.

Three weeks and 6 weeks after gonadectomy, short photoperiod and long photoperiod gonadectomized males, respectively, were implanted with blank, testosterone-filled, or oestradiol-filled capsules. Capsules were placed subcutaneously in the interscapular area via a small incision that was closed with a wound clip and treated with Furacin. Voles were anaesthetized with methoxyflurane vapours (Metofane: Pitman Moore, Washington, NJ) before implantation of capsules.

\section{Apparatus}

Odour preferences were tested in a covered Plexiglas Y-maze $(149 \mathrm{~cm} \times 9 \mathrm{~cm} \times 13 \mathrm{~cm})$ consisting of an acclimatization area, $15 \mathrm{~cm}$ long at the stem of the $Y$, a common arm $73 \mathrm{~cm}$ in length, and two choice arms each $76 \mathrm{~cm}$ long. Odourants were placed inside wire baskets in $15 \mathrm{~cm}$ chambers at the distal end of each choice arm. These baskets allowed air passage but prevented direct contact of the vole with the cotton. A fan located behind the acclimatization area pulled air through the $\mathrm{Y}$-maze toward the vole. Air movement measured with a hot-wire anemometer was $0.60 \mathrm{~m} \mathrm{~s}^{-1}$ through the common arm, and $0 \cdot 30 \mathrm{~m} \mathrm{~s}^{-1}$ through the choice arms. Further details of the apparatus can be found in Ferkin \& Zucker (1991).

\section{Odour preference procedure}

Voles were placed in the acclimatization area behind a moveable screen door for $1 \mathrm{~min}$ before the door was raised and they were exposed to two air currents from the separate arms of the maze. The odour stimuli in the maze arms were provided by cotton nesting material taken from a cage that housed a single animal for at least the preceding $24 \mathrm{~h}$. Each piece of cotton bedding impregnated with stimulus odours was placed in one of the two wire baskets, randomized with respect to maze arms. Cotton pieces were of similar size, weighed 8-10 g, and were not used in more than four consecutive trials. The Y-maze was cleaned between trials with ethanol.

\section{Odour preference tests}

Odour preference tests began three weeks after the implantation of the Silastic capsules. Odour donors were intact, gonadectomized, and gonadectomized plus hormone-treated males from each photoperiod. Odour recipients (receivers) were long photoperiod intact females. Odour donors and receivers were of similar age at the time of testing.

The influence of gonadal hormones on the attractiveness of male odours was examined by determining the effects of gonadectomy on odour cues emitted by long photoperiod and short photoperiod males. A particular male odour was judged attractive to a long-day female if she preferred it to a second odour available concurrently. Long photoperiod females chose between the odours of long photoperiod gonadectomized and long photoperiod intact males, long photoperiod gonadectomized males and short photoperiod intact males, and short photoperiod gonadectomized and short photoperiod intact males. We then examined the effects of gonadal hormone treatment on odour cues emitted by long photoperiod and short photoperiod males. Long photoperiod females chose between odours of males: (i) long photoperiod gonadectomized plus testosterone-treated and long photoperiod intact, (ii) short photoperiod gonadectomized plus testosterone-treated and long photoperiod intact, (iii) long photoperiod gonadectomized plus oestradiol-treated and tong photoperiod intact, (iv) short photoperiod gonadectomized plus oestradiol-treated and long photoperiod intact, (v) long photoperiod gonadectomized plus blank capsule and long photoperiod intact, (vi) short photoperiod gonadectomized plus blank capsule and long photoperiod intact, (vii) long photoperiod gonadectomized plus testosterone-treated and long photoperiod, gonadectomized plus blank capsule, (viii) long photoperiod gonadectomized plus oestradiol-treated and long photoperiod gonadectomized plus blank capsule, (ix) short photoperiod gonadectomized plus testosterone-treated and short photoperiod gonadectomized plus blank capsule and $(\mathrm{x})$ long photoperiod gonadectomized plus blank capsule and short photoperiod gonadectomized plus testosterone-treated.

A different group of 16 long photoperiod females was used for each odour test. At the completion of the final odour test, intact short photoperiod and long photoperiod male odour donors were administered a lethal dosage of sodium pentobarbitone, their testes removed and weighed to assess reproductive status. 


\section{Statistical analysis}

During each $5 \mathrm{~min}$ trial the initial odour choice of the vole, and time spent in the choice arms were recorded to the nearest second. Wilcoxon matched-pairs signed-ranks tests assessed the significance between the paired sets of observations (two-tailed $\alpha=0.05$ ). Each vole was considered to indicate an odour preference if it spent significantly more time in the maze arm containing that odour. The source of individual cotton odour stimuli was unknown to the experimenter at the time of testing.

\section{Results}

Paired testes weights were significantly lower in short photoperiod than in long photoperiod males $(240 \pm 80 \mathrm{mg}$ versus $1300 \pm 90 \mathrm{mg} ; t=10 \cdot 85, d . f .=22, P<0.001)$, confirming that short daylengths arrest gonadal growth in meadow voles (Dark et al., 1990).

Female voles did not display a left- or right-sided bias in their odour choices $\left(\chi^{2}=0 \cdot 67, d . f \cdot=\right.$ l, $P>0.05$ ). Moreover, the initial choice by the vole of an odour often coincided with the eventually preferred odour across all tests $\left(\chi^{2}=9.38, P<0.001\right)$. In all cases, the animals tested investigated both arms of the maze.

Gonadectomy affected attractiveness of odours emitted by long photoperiod, but not short photoperiod males. In every instance, odour attractiveness was based on odour preferences of long photoperiod intact females. Odours of long photoperiod intact males were more attractive than those of long photoperiod gonadectomized males ( $\operatorname{lm}>\operatorname{lmx}$; Fig. 1), and long photoperiod gonadectomized males emitted odours that were more attractive than those of short photoperiod intact males $(\operatorname{lmx}>\mathrm{sm}$; Fig. 1). The odours of short photoperiod intact males and short photoperiod plus gonadectomized males did not differ in attractiveness (sm versus smx; Fig. 1).

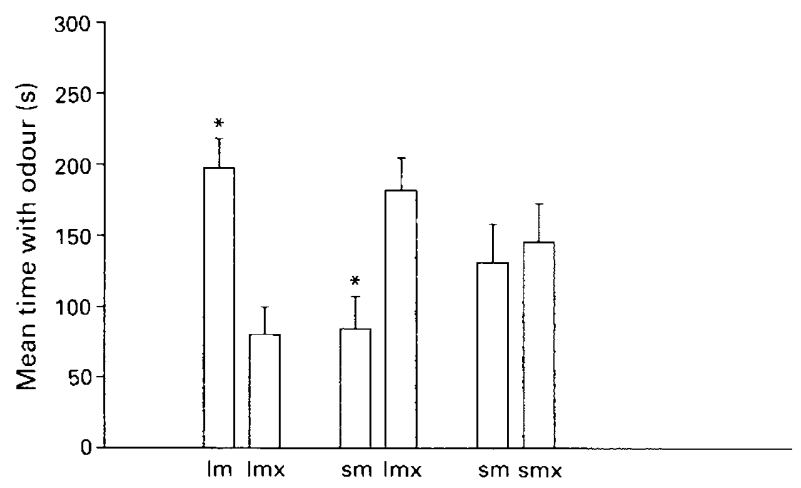

Fig. 1. Time spent (mean \pm SEM) by long-photoperiod female meadow voles with long photoperiod male $(\operatorname{lm})$ versus long photoperiod gonadectomized male $(\operatorname{lmx})$, short photoperiod male $(\mathrm{sm})$ versus $\operatorname{lmx}$, and $\mathrm{sm}$ versus short photoperiod gonadectomized male $(\mathrm{smx})$ odours; $n=16$ voles for each paired comparison. *indicates significant difference between odour pairs: Wilcoxon matched-pairs signed-ranks test at $P<0.05$ in this and subsequent figures.

Gonadal hormonal replacement affected attractiveness of long photoperiod, but not short photoperiod male odours. Both testosterone and oestradiol restored the attractiveness of odours in gonadectomized males kept in long photoperiods: odours of long photoperiod gonadectomized plus oestradiol-treated and long photoperiod intact males (lmxe versus $\operatorname{lm}$; Fig. 2), and long photoperiod, gonadectomized plus testosterone-treated and long photoperiod intact males (lmxt versus Im; Fig. 2) did not differ in attractiveness. However, odours of long photoperiod intact males were more attractive than those of short photoperiod gonadectomized plus oestradiol-treated ( $\mathrm{lm}>$ smxe; Fig. 2), or short photoperiod gonadectomized plus testosterone-treated males ( $\operatorname{lm}>$ smxt; Fig. 2). Blank capsules did not alter attractiveness of male odours: long photoperiod 
gonadectomized plus blank capsule were more attractive than short photoperiod gonadectomized plus testosterone odours ( $\operatorname{lmxb}>\operatorname{smxt}$; Fig. 3), but long photoperiod intact were more attractive than long photoperiod gonadectomized plus blank capsule odours ( $\operatorname{lm}>\operatorname{lmxb}$ ) and short photoperiod gonadectomized and blank capsule ( $1 \mathrm{~m}>\mathrm{smxb}$; Fig. 3). Long photoperiod gonadectomized plus testosterone-treated and long photoperiod gonadectomized plus oestradiol-treated odours were more attractive than long photoperiod gonadectomized plus blank capsule odours (lmxt and Imxe $>$ Imxb; Fig. 4), but the odours of short photoperiod gonadectomized plus testosteronetreated and short photoperiod gonadectomized plus blank capsule treated males did not differ in their attractiveness to long photoperiod females (smxt versus smxb; Fig. 4).

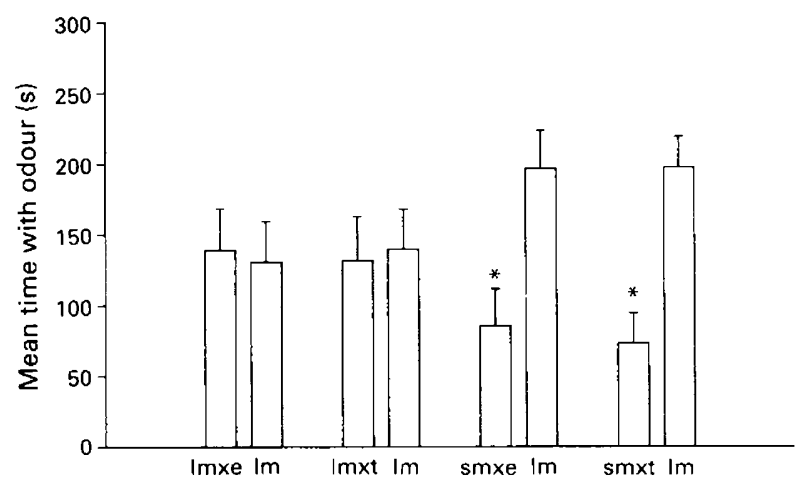

Fig. 2. Time spent by long photoperiod female voles with long photoperiod gonadectomized plus oestradiol-treated male (lmxe) versus $\mathrm{lm}$, long photoperiod gonadectomized plus testosteronetreated (lmxt) versus $\mathrm{lm}$, short photoperiod gonadectomized plus oestradiol-treated (smxe) versus $\mathrm{lm}$, and short photoperiod gonadectomized plus testosterone-treated (smxt) versus $\mathrm{lm}$ odours. Abbreviations as in Fig. 1.

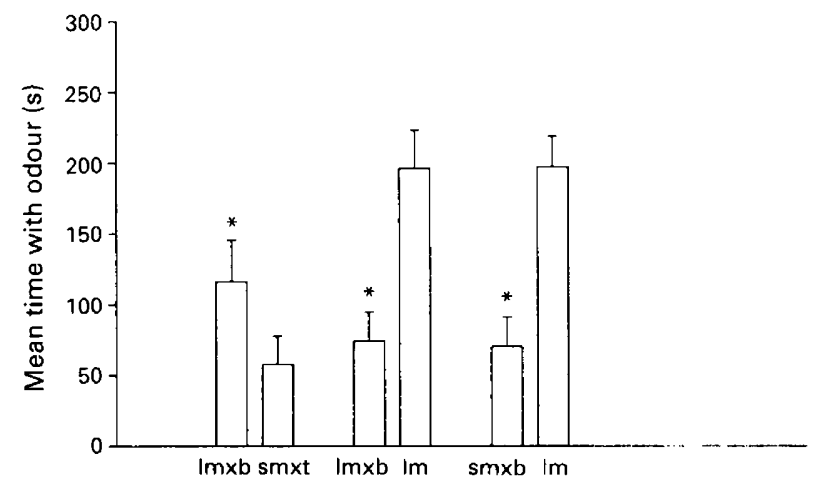

Fig. 3. Time spent by long photoperiod female voles with long photoperiod gonadectomized plus blank capsule male ( $\operatorname{lmxb}$ ) versus smxt, $\operatorname{lmxb}$ versus $\mathrm{lm}$, and short photoperiod gonadectomized plus blank capsule (smxb) versus Im odours. Abbreviations as in Fig. 1.

\section{Discussion}

The data indicate that androgens affect the odours emitted by male meadow voles kept in long photoperiods. The female-attractant cue in male odours was reduced or eliminated after 


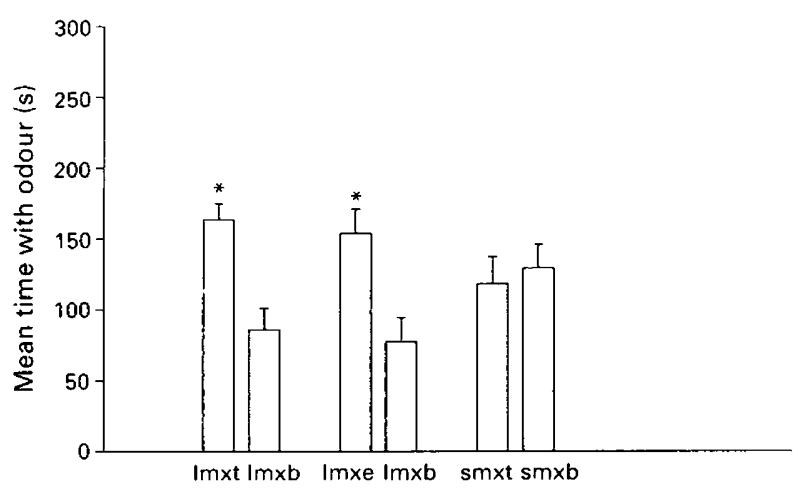

Fig. 4. Time spent by long photoperiod female voles with $\operatorname{lmxt}$ versus $\operatorname{lm} x b$, $1 \mathrm{mxe}$ versus $\operatorname{lm} x b$, and smxt versus smxb odours. Abbreviations as in Fig. 1.

gonadectomy, and was reinstated by testosterone treatment. These results support and extend the previous observations that changes in testicular function induced by photoperiod alter the femaleattractant cues of male odours (Ferkin \& Zucker, 1991). In related experiments, male-attractant odour cues of female voles and preferences for male odours were eliminated by ovariectomy and re-established by oestradiol treatment (Ferkin \& Zucker, 1991; Ferkin et al., 1991). When considered together, these studies suggest that seasonal differences in olfactory stimuli emitted by males and females are mediated by photoperiod changes in gonadal hormone secretion. In other rodent species, gonadectomy also reduces the attractiveness of odours to the opposite sex, the amounts of olfactory investigation, and scent marking; replacement with gonadal hormones reinstated these behaviours (Scott \& Pfaff, 1970; Brown, 1978; Albers \& Rowland, 1989; Johnston, 1990; Miernicki et al., 1990).

The odour cues of gonadectomized and short photoperiod intact males appeared to be equally unattractive to long photoperiod females. Treatment with testosterone was ineffective in increasing attractiveness of odours of short photoperiod males. In contrast, in females housed in short photoperiods, oestradiol therapy increased male-attractant potential of female odours (Ferkin et al., 1991). In female, but not male, meadow voles the seasonal differences in odour attractiveness primarily reflect a decrease in gonadal hormone secretion. In males, a decrease in substrate responsiveness to hormones mediated by photoperiod may also contribute to the decreased attractiveness of odours emitted in the fall and winter. The hormonal and neural changes that underlie this phenomenon are unknown and may involve interactions among components of the hypothalamicpineal-pituitary axis. Similar results and interpretations have been suggested to account for the inability of gonadal hormones to affect odour preferences of female meadow voles (Ferkin \& Zucker, 1991), and scent marking, social and copulatory behaviour in male golden hamsters (Mesocricetus auratus), in short photoperiods (Morin \& Zucker, 1978; Miernicki et al., 1990).

The increased odour attractiveness of long photoperiod rather than short photoperiod males may not depend solely on differences in testicular androgen secretions; long photoperiod females found odour cues of long photoperiod gonadectomized males more attractive than those of short photoperiod males. Long daylengths appear to be sufficient to induce a female-attractant cue, albeit less so in castrated males. Adrenal androgens, and pituitary hormones such as gonadotrophins, prolactin and $\alpha$-melanocyte-stimulating hormone $(\alpha-\mathrm{MSH})$ may also affect the secretion of odiferous substances or the glands in the integument (Strauss \& Ebling, 1970; Brown, 1985b); concentrations of these and other hormones probably differ in voles kept in long and short photoperiods. For example, prolactin concentrations are higher in long photoperiod than in short photoperiod male meadow voles (Smale et al., 1990), and castration does not affect the serum concentrations of prolactin in long photoperiod male hamsters (Bartke et al., 1978). $\alpha$-MSH 
influences sebaceous glands, thereby affecting the attractiveness of the odour cue (Thody \& Shuster, 1975). As in other rodents (Ebling et al., 1975; Thody et al., 1976), the synergism between pituitary hormones and androgens may enhance production and secretion of odoriferous substances in intact and hormone-treated long photoperiod male meadow voles.

Oestradiol treatment was effective in inducing a female-attractant cue in odours of males kept in long photoperiods. Aromatization of testosterone to oestradiol may be necessary to facilitate release of attractant cues in male meadow voles. Treatment with nonaromatizable androgens will be required to test this hypothesis. Oestradiol enanthate had only limited effects on maintenance of the preputial gland of montane voles (M. montanus) (Rowsemitt et al., 1988). In male rats and hamsters, the activation of sexual behaviour and olfactory investigation appear to involve aromatization of testosterone to oestrogen (Baum \& Vreeburg, 1973; Christensen et al., 1973; Södersten et al., 1986). Yet, in some male primates, guinea-pigs and rabbits, testosterone acts on androgen receptors and conversion to oestradiol is not part of the process by which these behaviours are affected (Strauss \& Ebling, 1970; Phoenix et al., 1973; Alsum \& Goy, 1974; Michael et al., 1990).

Gonadal hormones may affect odour cues of males by modifying odour-secreting tissues in the integument or altering the responsiveness of neural systems that mediate the behaviours necessary for odour emission. Male odours can affect the behaviour of females (Clulow \& Mallory, 1970; Mallory \& Clulow, 1977; Brown, 1985a, b; Carter et al., 1987). The preference of a female meadow vole for male odours is related to her hormonal state: females prefer the odour of adult males to those of other conspecifics in the breeding season, but prefer female to male odours in the nonbreeding season (Ferkin \& Seamon, 1987; Ferkin \& Zucker, 1991). Moreover, males prefer female odours during the breeding, but not during the nonbreeding, season (Ferkin \& Seamon, 1987, Ferkin \& Gorman, 1992). Thus, odour cues and odour preferences may facilitate reproduction, and female territoriality in long days, and communal nesting and reproductive quiescence in short days.

We thank L. Smale for criticism of the manuscript, G. Brooks, D. Starks, and E. Moore for excellent animal care and S. Ferkin, F. Ferkin and C. Kuzdowicz for technical assistance. This research was supported by NRSA postdoctoral fellowship 1F32NS08792-01 to M. H. Ferkin, an NSF graduate fellowship to M. R. Gorman, and NIH grant HD 02982.

\section{References}

Adams, M.R., Tamarin, R.H. \& Callard, I.P. (1980) Seasonal changes in plasma androgen levels and the gonads of the beach vole, Microtus breweri. General and Comparative Endocrinology 41, 31-40.

Albers, H.E. \& Rowland, C.M. (1989) Ovarian hormones influence odor stimulated flank marking behavior in the hamster (Mesocricetus auratus). Physiology and Behavior 45, 113117.

Alsum, P. \& Goy, R.W. (1974) Actions of esters of testosterone, dihydrotestosterone or estradiol on sexual behavior in castrated male guinea pigs. Hormones and Behaviour 5, 207-217.

Bartke, A., Goldman, B.D., Bex, F.J. \& Dalterio, S. (1978) Mechanisms of reversible loss of reproductive capacity in a seasonally-breeding mammal. International Journal of Andrology Supplement 2, 345-353.

Baum, M.J. \& Vreeburg, J.T.M. (1973) Copulation in male rats following combined treatment with estradiol and dihydrotestosterone. Science $N Y \mathbf{1 8 2}$, 283-284.

Brown, R.E. (1978) Hormonal control of odor preferences and urine-marking in male and female rats. Physiology and Behavior 20, 21-24.
Brown, R.E. ([985a) The rodents I: effects of odours on reproductive physiology (primer effects). In Social Odours in Mammals, Vol. 1, pp. 245-344. Eds R. E. Brown \& D. W. Macdonald. Oxford University Press, Oxford.

Brown, R.E. (1985b) The rodents II: suborder Myomorpha. In Social Odours in Mammals, Vol. 1, pp. 345-457. Eds R. E. Brown \& D. W. Macdonald. Oxford University Press, Oxford.

Carter, S.C., Witt, D.M., Schneider, J., Harris, Z.L. \& Volkening, D. (1987) Male stimuli are necessary for female sexual behavior and uterine growth in prairie voles (Microtus ochrogaster). Hormones and Behavior 21, 74-82.

Christensen, L.W., Coniglio, L.P., Paup, D.C. \& Clemens, L.G. (1973) Sexual behavior of male golden hamsters receiving diverse androgen treatments. Hormones and Behaviour 4, 223-229.

Christian, J.J. (1980) Regulation of annual rhythms of reproduction in temperate small rodents. In Testicular Development, Structure and Function, pp. 367--380. Eds A. Steinberger \& E. Steinberger. Raven Press, New York. 
Christiansen, E., Wiger, R. \& Eilersten, E. (1978) Morphological variations in the preputial gland of wild bank voles, Clethrionomys glareolus. Holarctic Ecology 1, 321 -325.

Clulow, F.V. \& Mallory, F.F. (1970) Oestrus and induced ovulation in the meadow vole, Microtus pennsylvanicus. Journal of Reproduction and Fertility 23, 341-343.

Dark, J., Spears, N., Whaling, C.S., Wade, G.N., Meyer, J.S. \& Zucker, I. (1990) Long day lengths promote brain growth in meadow voles. Developmental Brain Research 53, 264-269.

Ebling, F.J. (1972) The response of the cutaneous glands to steroid hormones. General and Comparative Endocrinology Supplement 3, 228-237.

Ebling, F.J., Ebling, E., Randall, V. \& Skinner, J. (1975) The effects of hypophysectomy and of bovine growth hormone on the responses to testosterone of prostate, preputial, Harderian and lachrymal glands and of brown adipose tissue in the rat. Journal of Endocrinology 66, 401-406.

Ferkin, M.H. (1988) Seasonal differences in social behavior among adult and juvenile meadow voles, Microtus pennsylvanicus. Ethology 79, 116-125.

Ferkin, M.H. \& Seamon, J.O. (1987) Odor preferences and social behavior in meadow voles, Microtus pennsylvanicus: seasonal differences. Canadian Journal of Zoology 65, 2931-2937.

Ferkin, M.H. \& Gorman, M.R. (1992) Photoperiod and gonadal hormones influence odor preferences of the male meadow vole, Microtus pennsy/vanicus. Physiology and Behavior 51, 1087-1091.

Ferkin, M.H., Gorman, M.R. \& Zucker, I. (1991) Ovarian hormones influence odor cues emitted by female meadow voles, Microtus pennsylvanicus. Hormones and Behaviour 25, 572-581.

Ferkin, M.H. \& Zucker, I. (1991) Seasonal control of ovarian preferences of meadow voles (Microtus pennsylvanicus) by photoperiod and ovarian hormones. Journal of Reproduction and Fertility 92, $433-441$.

Fleming, A.S., Phillips, A., Rydall, A. \& Levesque, L. (1988) Effects of photoperiod, the pineal gland and the gonads on agonistic behavior in female golden hamsters (Mesocricetus auratus). Physiology and Behavior 44, 227-234.

Jannett, F.J., Jr (1978) Dosage response of the vesicular, preputial, anal, and hip glands of the male vole, Microtus montanus (Rodentia: Muridae), to testosterone propionate. Journal of Mammalogy 59, 772-779.

Johnston, R.E. (1990) Chemical communication in golden hamsters: from behavior to molecules and neural mechanisms. In Contemporary Issues in Comparative Psychology, pp. 381-409. Ed. D. A. Dewsbury. Sinauer Press, Sunderland, Massachusetts.

Keverne, E.B. (1981) The accessory olfactory system and its role in pheromonally mediated changes in prolactin. In Olfaction and Endocrine Regulation, pp. 127-140. Ed. W. Breipohl. IRL Press, Ltd, London.

Madison, D.M. \& McShea, W.J. (1987) Seasonal changes in reproductive tolerance, spacing, and social organization in meadow voles: a microtine model. American Zoologist 27, 899-908.
Mallory, F.F. \& Clulow, F.V. (1978) Evidence of pregnancy failure in the wild meadow vole, Microtus pennsylvanicus. Canadian Journal of Zoology 55, $1-17$.

Michael, R.P., Zumpe, D. \& Bonsall, R.W. (1990) Estradiol administration and the sexual activity of castrated male rhesus monkeys (Macaca mulatta). Hormones and Behavior 24, 71-88.

Miernicki, M., Pospichal, M.W. \& Powers, J.B. (1990) Short photoperiods affect male hamster sociosexual behaviors in the presence and absence of testosterone. Physiology and Behavior 47, 95-106.

Morin, L.P. \& Zucker, I. (1978) Photoperiodic regulation of copulatory behaviour in the hamster. Journal of Endocrinology 77, 249-258.

Phoenix, C.H., Slob, A.K. \& Goy, R.W. (1973) Effects of castration and replacement therapy on sexual behavior of adult male rhesus. Journal of Comparative and Physiological Psychology 84, 472-48I.

Powers, J.B., Bergondy, M.L. \& Matochik, J.A. (1985) Male hamster sociosexual behaviours: effects of testosterone and its metabolites. Physiology and Behavior $35,607 \cdots 16$.

Quay, W.B. (1968) The specialized posterolateral sebaceous glandular regions in microtine rodents. Journal of Mammalogy 49, 427-445.

Rowsemitt, C.N. \& Berger, P.J. (1983) Diel plasma testosterone rhythms in male Microtus montanus, the montane vole, under long and short photoperiods. General and Comparative Endocrinology 50, 354-358.

Rowsemitt, C.N., Walsh, C.J., Kuehl, M.C., Moore, R.E. \& Jackson, L.L. (1988) Hormonal regulation of preputial gland function in male Microtus montanus, the montane vole. Comparative Biochemistry and Physiology 90A, 195--200.

Scott, J.W. \& Pfaff, D.W. (1970) Behavioral and electrophysiological responses of female mice to male urine odors. Physiology and Behavior 5, 407-411.

Smale, L., Lee, T.M., Nelson, R.J. \& Zucker, I. (1990) Prolactin counteracts effects of short day lengths on pelage growth in the meadow vole, Microtus pennsylvanicus. Journal of Experimental Zoology 253, $186-188$.

Södersten, P., Eneroth, P., Hansson, T., Mode, A., Johannson, D., Näslund, B., Liang, T. \& Gustafsson, G. A. (1986) Activation of sexual behaviour in castrated rats: the role of oestradiol. Journal of Endocrinology 111, 455. 462.

Strauss, J.S. \& Ebling, F.J. (1970) Control and function of skin glands in mammals. Memoirs of Society for Endocrinology 18, 341 368.

Thody, A.J. \& Shuster, S. (1975) Control of sebaceous gland function in the rat by $\alpha$-melanocyte-stimulating hormone. Journal of Endocrinology 64, 503 510.

Thody, A.J., Cooper, M.F., Bowden, P.E., Meddis, D. \& Shuster, S. (1976) Effect of $\alpha$-melanocyte stimulating hormone and testosterone on cutaneous and modified sebaceous glands in the rat. Journal of Endocrinology $71,279-288$.

Received 22 May 1991 